\title{
Repellent Activities of Essential Oils of Some Plants Used Traditionally to Control the Brown Ear Tick, Rhipicephalus appendiculatus
}

\author{
Wycliffe Wanzala, ${ }^{1,2}$ Ahmed Hassanali, ${ }^{2,3}$ \\ Wolfgang Richard Mukabana, ${ }^{2,4}$ and Willem Takken ${ }^{5}$ \\ ${ }^{1}$ Department of Biological Sciences, School of Pure and Applied Sciences, South Eastern Kenya University, \\ P.O. Box 170-90200, Kitui, Kenya \\ ${ }^{2}$ Behavioural and Chemical Ecology Department, International Centre of Insect Physiology and Ecology, \\ African Insect Science for Food and Health, P.O. Box 30772-00100-GPO, Nairobi, Kenya \\ ${ }^{3}$ Chemistry Department, School of Pure and Applied Sciences, Kenyatta University, P.O. Box 43844-00100-GPO, Nairobi, Kenya \\ ${ }^{4}$ School of Biological Sciences, University of Nairobi, P.O. Box 30197-00100-GPO, Nairobi, Kenya \\ ${ }^{5}$ Laboratory of Entomology, Wageningen University and Research Centre, P.O. Box 8031, 6700 EH Wageningen, The Netherlands
}

Correspondence should be addressed to Wycliffe Wanzala; osundwal@yahoo.com

Received 12 October 2013; Revised 16 December 2013; Accepted 17 December 2013; Published 19 February 2014

Academic Editor: C. Genchi

Copyright ( 12014 Wycliffe Wanzala et al. This is an open access article distributed under the Creative Commons Attribution License, which permits unrestricted use, distribution, and reproduction in any medium, provided the original work is properly cited.

\begin{abstract}
Essential oils of eight plants, selected after an ethnobotanical survey conducted in Bukusu community in Bungoma County, western Kenya (Tagetes minuta, Tithonia diversifolia, Juniperus procera, Solanecio mannii, Senna didymobotrya, Lantana camara, Securidaca longepedunculata, and Hoslundia opposita), were initially screened (at two doses) for their repellence against brown ear tick, Rhipicephalus appendiculatus, using a dual-choice climbing assay. The oils of T. minuta and T. diversifolia were then selected for more detailed study. Dose-response evaluations of these oils showed that T. minuta oil was more repellent $\left(\mathrm{RD}_{50}=0.0021 \mathrm{mg}\right)$ than that of T. diversifolia $\left(\mathrm{RD}_{50}=0.263 \mathrm{mg}\right)$. Gas chromatography-linked mass spectrometric $(\mathrm{GC}-\mathrm{MS})$ analyses showed different compositions of the two oils. T. minuta oil is comprised mainly of cis-ocimene (43.78\%), dihydrotagetone (16.71\%), piperitenone (10.15\%), trans-tagetone (8.67\%), 3,9-epoxy-p-mentha-1,8(10)diene (6.47\%), $\beta$-ocimene (3.25\%), and cis-tagetone (1.95\%), whereas T. diversifolia oil is comprised mainly of $\alpha$-pinene (63.64\%), $\beta$-pinene (15.00\%), isocaryophyllene (7.62\%), nerolidol (3.70\%), 1tridecanol (1.75\%), limonene (1.52\%), and sabinene (1.00\%). The results provide scientific rationale for traditional use of raw products of these plants in controlling livestock ticks by the Bukusu community and lay down some groundwork for exploiting partially refined products such as essential oils of these plants in protecting cattle against infestations with $R$. appendiculatus.
\end{abstract}

\section{Introduction}

In sub-Saharan Africa, East Coast fever (ECF), caused by Theileria parva parva, Theiler, 1904, and transmitted by the brown ear tick, Rhipicephalus appendiculatus, Neumann, 1901, is one of the major constraints to the development of the livestock industry $[1,2]$. Of the estimated 12.7 million head of cattle (both indigenous and exotic), 76\% are at risk to ECF [3]. The disease is associated with up to $10 \%$ mortality in zebu calves in ECF endemic areas and can cause up to $100 \%$ mortality in susceptible exotic and indigenous breeds $[3,4]$.
Prevention, control, and management of both vector and pathogen have continued to rely heavily on the application of synthetic chemical acaricides on the host since their introduction in 1902 in sub-Saharan Africa [5]. However, this has proved to be costly and unsustainable in a number of ways [1]. The acaricides can eliminate ticks from the host, but they do not prevent continued reinfestation from the source environment, where ticks spend $90 \%$ of their life. For effective management of harmful ticks, an integrated combination of tactics may need to be put in place that controls ticks on individual hosts as well as in the host environment in order 
to prevent host reinfestation during grazing. One possible strategy would be to use tick repellents on the host and tickrepellent plants in the pasture (host environment), combined with plants that are attractive to ticks such as Acalypha fruticosa Forssk. var. villosa Hutch (Family: Euphorbiaceae) surrounding the pasture land so as to develop a "push-pull" tick manipulation system $[6,7]$. Although the proposed strategy appears complex, it may be possible to achieve in zero/ semizero grazing, small-scale free-range, and tethering livestock farming systems. In others, such as pastoralism and large-scale livestock farming systems, the deployment of wellformulated repellents dispensed from controlled-release dispensers may be more practical.

$\mathrm{N}, \mathrm{N}$-diethyl-3-methylbenzamide (DEET) is still considered the best available product, repelling a wide variety of insects, ticks, and mites [8]. Though DEET is not expected to bioaccumulate, the amounts present in the environment have been shown to be toxic to some species of zooplankton and fish $[9,10]$. In humans, the repellent may cause insomnia, mood disturbances, impaired cognitive functions, seizures, toxic encephalopathy, and allergic reactions [11-13]. This has led to a search for alternative eco-friendly and effective repellents.

The potential of some local plants and plant products to repel ticks from grazing areas and host animals, respectively, has been demonstrated previously [14-18]. Melinis minutiflora (molasses grass), a tropical grass already in use as livestock fodder $[19,20]$, covers crop and mulch [21] and for thatching houses [22], it has been shown to be toxic [15] and repellent to ticks $[14,23,24]$ as well as insects and snakes [21]. One study demonstrating potential of molasses grass to control Amblyomma variegatum and $R$. appendiculatus, vectors of the livestock diseases heartwater (cowdriosis) and ECF, respectively, has been reported [24]. In addition, several other Kenyan local shrubs, including Cleome hirta and Gynandropsis gynandra, have demonstrated potential as tickrepellent pasture plants [25-27].

A number of studies have shown that plant-based repellents can be comparable to DEET or even better [28-32]. One commercial repellent product is the Flea and Tick Granular Repellent, which is made from essential oils of cedar, cinnamon, mint, and lemon grass; it has a pleasant odour and can be safely used outdoors for flea and tick control [33]. Essential oils of a number of other plants have been shown to be repellent to ticks. These include Commiphora erythraea and $C$. myrrh [34], Cleome monophylla [35], Ocimum suave [36], Cleome hirta [27], and G. gynandra [37].

Use of tick-repellent plants in pasture lands or essential oils on hosts and their integration with other off-host or onhost tick control measures could be practical and provide economic ways of controlling not only livestock ticks but also arthropod vectors [38-40]. In our previous survey of livestock tick control ethnopractices among Bukusu community in Bungoma district, western Kenya, we found widespread use of ethnobotanicals derived from local/native plants to control tick infestations on cattle [41]. Blends of botanicals from one or more plants are used either as on-host suspensions or burnt and smoke used to fumigate cattle. Our follow up objective has been to assess the repellence of essential oils of some of these plants against $R$. appendiculatus adults in the laboratory, to characterize the chemical constituent profiles of the more repellent ones, and then to initiate both off- and on-host evaluation of their efficacy in controlling the ticks in the field. In the present paper, we report the results obtained from repellence assays of essential oils of 8 plants against $R$. appendiculatus adults and results of a more detailed study of two selected plants, Tagetes minuta L. and Tithonia diversifolia (Hemsl.) A. Gray.

\section{Materials and Methods}

2.1. Selection of Eight Plant Species. An ethnobotanical survey was previously conducted in the Bukusu community in Bungoma County, western Kenya, along the southern slopes and foothills of Mount Elgon at altitudes ranging from about $1,300 \mathrm{~m}$ in the south to about 3,500 $\mathrm{m}$ in the north [41]. The County is located between latitude $0^{\circ} 25^{\prime} \mathrm{S}$ and $0^{\circ} 53^{\prime} \mathrm{N}$ and longitude $34^{\circ} 21^{\prime} \mathrm{W}$ and $35^{\circ} 04^{\prime} \mathrm{E}$. Specimens of $\sim 157$ plant species, which were documented to have varied effects on livestock ticks [41], were collected for taxonomic examination at the herbarium of the School of Biological Sciences, University of Nairobi, Kenya. The potential efficacy of each plant species in protecting cattle against tick infestations was assessed following a four-level protocol proposed by Heinrich and coworkers [42], and eight plant species were selected for initial laboratory screening $[41,43]$. Voucher specimens of these plants were deposited at the University of Nairobi Herbarium, and comprised of Tagetes minuta L. (029-BGMMwi/2002), Tithonia diversifolia (Hemsl.) A. Gray (015-BGMMuf/2002), Juniperus procera Endl. (134-BGM-Elg/2002), Solanecio manii (Hook. f.) C. Jeffrey. (106-BGM-Mwi/2002), Senna didymobotrya (Fresen.) H. S. Irwin and Barneby (132BGM-Web/2002), Lantana camara L. (043-BGM-Mwi/2002), Securidaca longepedunculata Fres. (018-BGM-Mec/2002), and Hoslundia opposita Vahl. (133-BGM-Bul/2002).

2.2. Experimental Ticks. The ticks used (the brown ear tick, Rhipicephalus appendiculatus Neumann, 1901) were obtained from the colonies at the International Livestock Research Institute (ILRI) and bred in the insectary at ICIPE, Nairobi, Kenya. Rearing conditions and management of ticks were as described previously $[44,45]$. All the experiments were conducted using the newly emerged adult ticks of mixed sexes.

2.3. Isolation of Essential Oils. The aerial parts of each of the eight plants were collected from the southern slopes and foothills of Mount Elgon in western Kenya during the month of August and allowed to dry in a well-ventilated room for 1-2 weeks. Each plant material was cut into small pieces and about $1 \mathrm{~kg}$ was hydrodistilled using a Clevenger-type apparatus for $8 \mathrm{~h}$ [46]. Essential oil of each plant was collected in $2 \mathrm{~mL}$ vials and stored at $-20^{\circ} \mathrm{C}$ in a freezer until required for bioassays or analyses.

2.4. Dual-Choice Repellence Assays. A dual-choice tick repellence climbing assay [47] that exploits the behaviour of $R$. appendiculatus to climb up grass stems to await potential 
hosts passing by $[48,49]$ was used. The repellence of essential oils of the eight plants against $R$. appendiculatus was first compared at $0.1 \mathrm{mg}$ and $50 \mathrm{mg}$ doses. The most repellent oils (that of T. minuta and that of T. diversifolia) were then selected for more detailed study. These plants are also highly ranked by livestock holders of Bukusu community in livestock tick prevention and control [41]. The oils of the plants were diluted serially with dichloromethane (GC grade) to provide $0.5 \mathrm{mg}$ to $0.00005 \mathrm{mg} / 10 \mu \mathrm{L}$ of solutions. An aliquot of $20 \mu \mathrm{L}$ of each dose was applied to filter paper strip on the glass tubes, with an equivalent volume of dichloromethane added to the control filter paper strip. The-set up was allowed to equilibrate for 30 min before five adult $R$. appendiculatus of mixed age and sex were released on the base of the climbing set-up assay [47]. Observations were made over a 1-hour period, and the number of ticks above the filter paper strip on the control glass tube $(\mathrm{Nc})$ and on the glass tube with test materials $(\mathrm{Nt})$ was recorded at 15, 30, 45, and $60 \mathrm{~min}$. Twenty replicates for each dose were carried out, each time with fresh, naïve adult ticks. Initial comparison of the responses of ticks in the set-up with and without residual dichloromethane on both sides showed no bias for either side and no effects of the residual solvent on the adult ticks. The repellency of each dose was calculated using the formula: (number of ticks in control arm number of ticks in treated arm/total responding ticks) $\times 100$. Dose-response data were subjected to probit analysis using the $\%$ repellencies from the replicated experiments [47].

\subsection{Determination of the Composition of T. minuta and $T$.} diversifolia Essential Oils. GC-MS analyses of the two oils were performed with a VG Masslab 12-250 quadruple gas chromatography-mass spectrometer. Chromatographic separations were achieved using a fused silica capillary column (Hewlett Packard, $50 \mathrm{~m} \times 0.32 \mathrm{~mm}$ ID) coated with Carbowax $20 \mathrm{M}(0.3 \mu \mathrm{m}$ film thickness) with helium as the carrier gas. All the GC-MS analyses were made in the splitless mode with helium as the carrier gas. The oven temperature was programmed from $60^{\circ} \mathrm{C}$ for $7 \mathrm{~min}$, to $120^{\circ} \mathrm{C}$ at $5^{\circ} \mathrm{C}$ per min, then to $180^{\circ} \mathrm{C}$ at $10^{\circ} \mathrm{C}$ per min, and finally to $220^{\circ} \mathrm{C}$ at $20^{\circ} \mathrm{C}$ per $\mathrm{min}$, where it was maintained for $10 \mathrm{~min}$. Constituents of the essential oils were identified by analysis of their mass spectra, direct comparison of these with those in the Wiley NBS and NIST databases, and coinjections with authentic standards (from Sigma Chemical Company, Poole, UK and Aldrich Chemical Company, Gillingham, UK) on a Hewlett Packard HP 5890A Gas Chromatograph equipped with a flame ionization detector (at $230^{\circ} \mathrm{C}$ ). A fused silica capillary column (Hewlett Packard, $50 \mathrm{~m} \times 0.22 \mathrm{~mm} \times 0.33 \mathrm{~mm} \mathrm{CD}$ ) coated with methyl silicon $(0.3 \mu \mathrm{m}$ film thickness) was used with nitrogen as the carrier gas. All GC analyses were performed in the splitless mode with the injector temperature at $270^{\circ} \mathrm{C}$ and oven temperature programme similar to that in GC-MS analyses.

2.6. Data Analysis. Dose-response data were subjected to simple regression and probit analysis using the percent

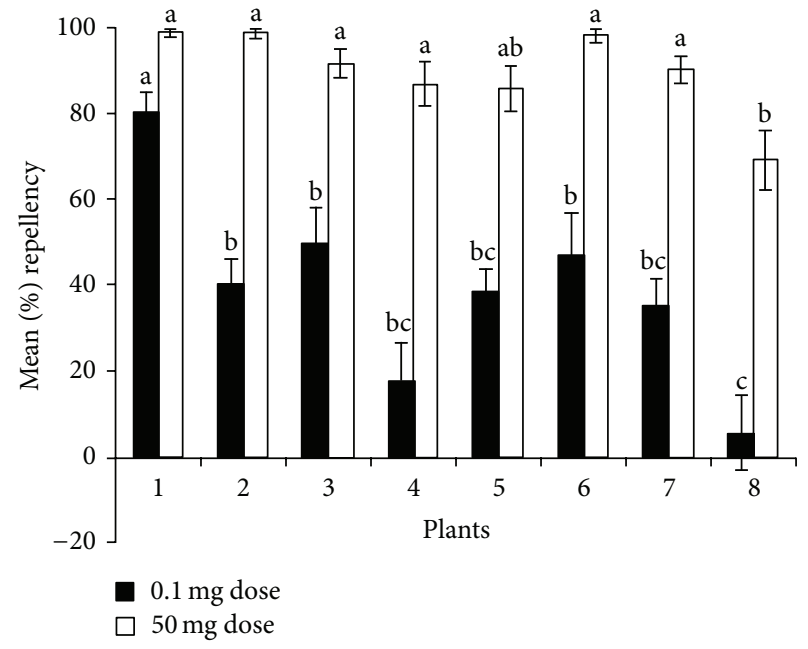

FIGURE 1: The repellent effect of essential oils of eight plants at doses of $0.1 \mathrm{mg}$ and $50 \mathrm{mg}$ (neat oil) against newly emerged Rhipicephalus appendiculatus adults. Plant species 1 is Tagetes minuta, 2 is Tithonia diversifolia, 3 is Hoslundia opposita, 4 is Solanecio mannii, 5 is Lantana camara, 6 is Juniperus procera, 7 is Senna didymobotrya and 8 is Securidaca longepedunculata. For a given repellent dose, means capped by the same alphabetical letters are not significantly different at $P<0.0001$ (Student-Newman-Keuls $H$ test).

repellency values obtained from replicated experiments and a regression model developed based on

$$
\text { Probit }[\Pi(\text { dose } 1)]=\beta_{0}+\beta_{1} x+\epsilon,
$$

where $\beta_{0}$ is the coefficient of the model representing $y$ intercept, $\beta_{1}$ is the coefficient of the model representing dosel, $x$ is the various concentrations of essential oils, dosel is the $\log _{10}$ (dose), $\epsilon$ is the error term (residual term) representing the difference between the actual observed value and that predicted by the model (the predictor (regressor) variable, $x$ is the dose of the essential oil), and $\Pi$ is the repellency probability.

Student-Newman-Keuls $H$ test was used to compare the mean values of repellency obtained for various doses of the repellent effects [50]. Percent repellency values were transformed into probabilities, while essential oil doses were transformed into logarithms to base 10 and lines for regression models fitted using R software for Microsoft windows. These models were used to estimate repellent effects of the two essential oils at $\mathrm{RD}_{50}$ and $\mathrm{RD}_{75}[8,51]$.

\section{Results}

3.1. Screening of the Essential Oils Isolated from the Selected Eight Plant Species. The results of repellency tests following the screening of the essential oils isolated from the eight plants (T. minuta, T. diversifolia, J. procera, S. mannii, S. didymobotrya, L. camara, S. longepedunculata, and H. opposita) at $0.1 \mathrm{mg}$ and $50 \mathrm{mg}$ doses are shown in Figure 1. Some variation was found in the repellent effect of the essential oils at the two doses with that of S. longepedunculata showing the least repellent effect at both doses and that of T. minuta showing the 
highest repellent effect at the lower dose $(80.1 \pm 4.7 \%)$. The essential oil of T. minuta and one of the other six plants ( $T$. diversifolia) were therefore selected for more detailed bioassay.

3.2. Dose-Response Repellency of the Essential Oils of T. minuta and $T$. diversifolia. The repellence of the two essential oils at different doses is shown in Figures 2(a) and 2(b). The essential oil of T. minuta was found to be significantly more repellent than that of $T$. diversifolia at all corresponding doses $(P<$ 0.05). In both the essential oils of T. minuta and T. diversifolia, there was significant correlation between repellence and dose (Pearson Correlation, $\alpha=0.01$ ). Model development of the bioassay data of the two essential oils allowed estimation of $\mathrm{RD}_{50}$ and $\mathrm{RD}_{75}$ (Table 2). Previous work at ICIPE, Nairobi, Kenya, tested various DEET doses under the same laboratory conditions as described previously [27, 35, 37] and determined their percent repellence against $R$. appendiculatus (Table 3), with which we compared the current dose-response repellencies caused by the essential oils of T. minuta and $T$. diversifolia.

3.3. Major Chemical Components of the Essential Oils of Tagetes minuta and Tithonia diversifolia. Gas chromatography (GC) in combination with gas chromatography/mass spectrometry (GC-MS) separated the chemical components in the mixtures of the essential oils of T. minuta and T. diversifolia plants, and the major representative GC/GCMS profiles are shown in Tables 1(a) and 1(b), respectively. The major chemical components of $T$. minuta essential oil were cis-ocimene $(43.78 \%)$, dihydrotagetone $(16.71 \%)$, piperitenone $(10.15 \%)$, trans-tagetone $(8.67 \%)$, 3.9-epoxyp-mentha-1.8(10)diene $(6.47 \%), \quad \beta$-ocimene $(3.25 \%)$, cistagetone $(1.95 \%)$, and $\beta$-caryophyllene $(0.84 \%)$. Those chemical components of the essential oil of $T$. diversifolia were mainly $\alpha$-pinene $(63.64 \%), \beta$-pinene $(15.00 \%)$, isocaryophyllene $(7.62 \%)$, nerolidol $(3.70 \%)$, 1-tridecanol (1.75\%), limonene (1.52\%), and sabinene (1.00\%).

\section{Discussion}

In a previous study, we undertook a survey of indigenous knowledge of the Bukusu community of western Kenya on livestock ticks, the risks they pose and ethnopractices associated with their management [41]. The study showed that the Bukusu community has accumulated rich ethnoveterinary knowledge and practices and that on-host use of ethnobotanical suspensions and fumigation of host animals with volatiles from burning plant products (prepared from one or more of $\sim 157$ plants) constitute important methods of controlling the ticks. In the present study, repellence of essential oils associated with some of the plants was used to assess one possible mode of action of the plant products on ticks. Eight of these plants were selected for screening against the adults of the brown ear tick following a four-level assessment protocol (based on additional ethnobotanical information on similar use of the plant elsewhere, reported phytochemical profile of the plant or related species, and any documented bioactivity

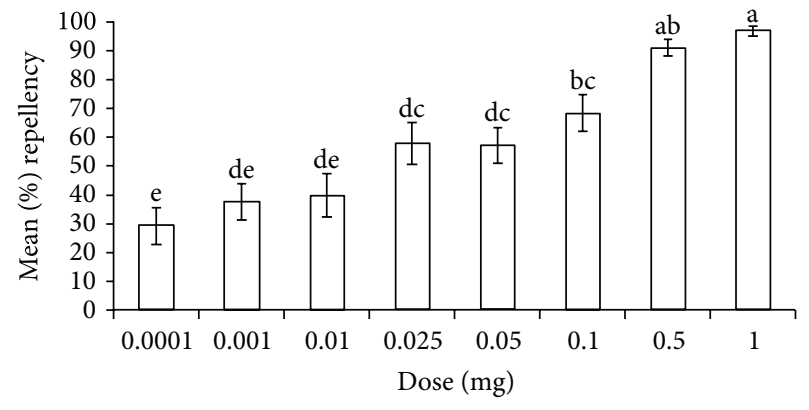

(a)

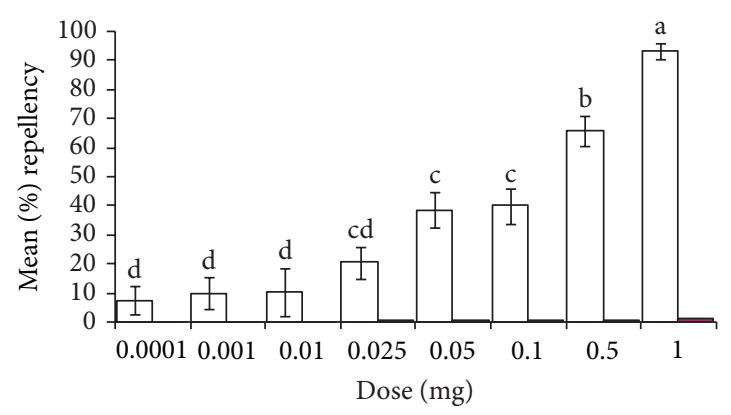

(b)

FIGURE 2: Mean repellency percentage of different doses of Tagetes minuta (a) and Tithonia diversifolia (b) essential oils against newly emerged adults, Rhipicephalus appendiculatus, in a dual-choice assay. Means with the same alphabetical letters are not significantly different at $P<0.0001$ (Student-Newman-Keuls $H$ test).

data of the plant extracts or their phytochemicals) proposed by Heinrich and coworkers [42]. The essential oils of these plants showed some variation in repellence against newly emerged $R$. appendiculatus adult ticks. This was particularly apparent at the lower dose $(0.1 \mathrm{mg})$, with the essential oil of T. minuta showing the highest repellence and that of S. longepedunculata showing the least repellent effect.

Comprehensive repellence studies with T. minuta and $T$. diversifolia oils at eight doses confirmed the higher repellence of the former against $R$. appendiculatus. Interestingly, its repellent effect is comparable to that of commonly used repellent DEET at $0.1 \mathrm{mg}$ dose (with essential oil of T. minuta producing a repellent effect of $80.1 \pm 4.9 \%$ compared with that of $\mathrm{DEED}, 84.0 \pm 3.9 \%)$. Additionally, the results obtained by this study are compared favourably with the results reported by Nchu and coworkers [52] for the essential oil of T. minuta plants growing in Pretoria, South Africa, against Hyalomma rufipes Koch. H. rufipes is also widely distributed in Africa and can transmit disease-causing viral and protozoan (e.g., Crimean-Congo haemorrhagic fever and Babesia, resp.) pathogens to livestock and humans alike $[53,54]$. Although the T. minuta oil obtained in the present study shares a series of major constituents (e.g., cis-ocimene, dihydrotagetone, piperitenone, tagetone, and $\beta$-ocimene) with that isolated in Pretoria, South Africa [52], there are also some chemotypic differences between the two, reflected in different proportions of these compounds and the presence of some constituents in one chemotype (e.g., 3-methyl-2-(2-methyl-2-butenyl)-furan 


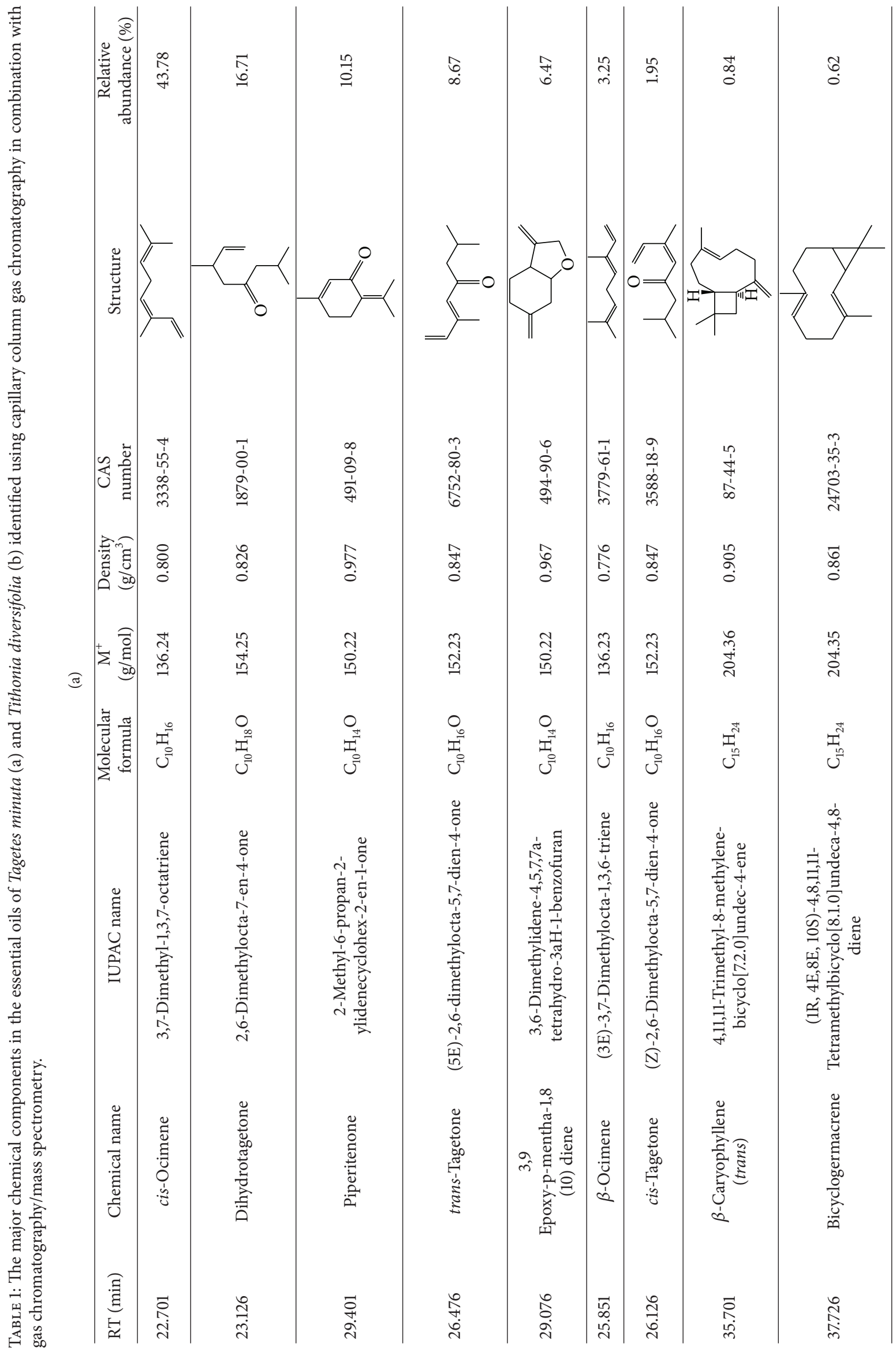




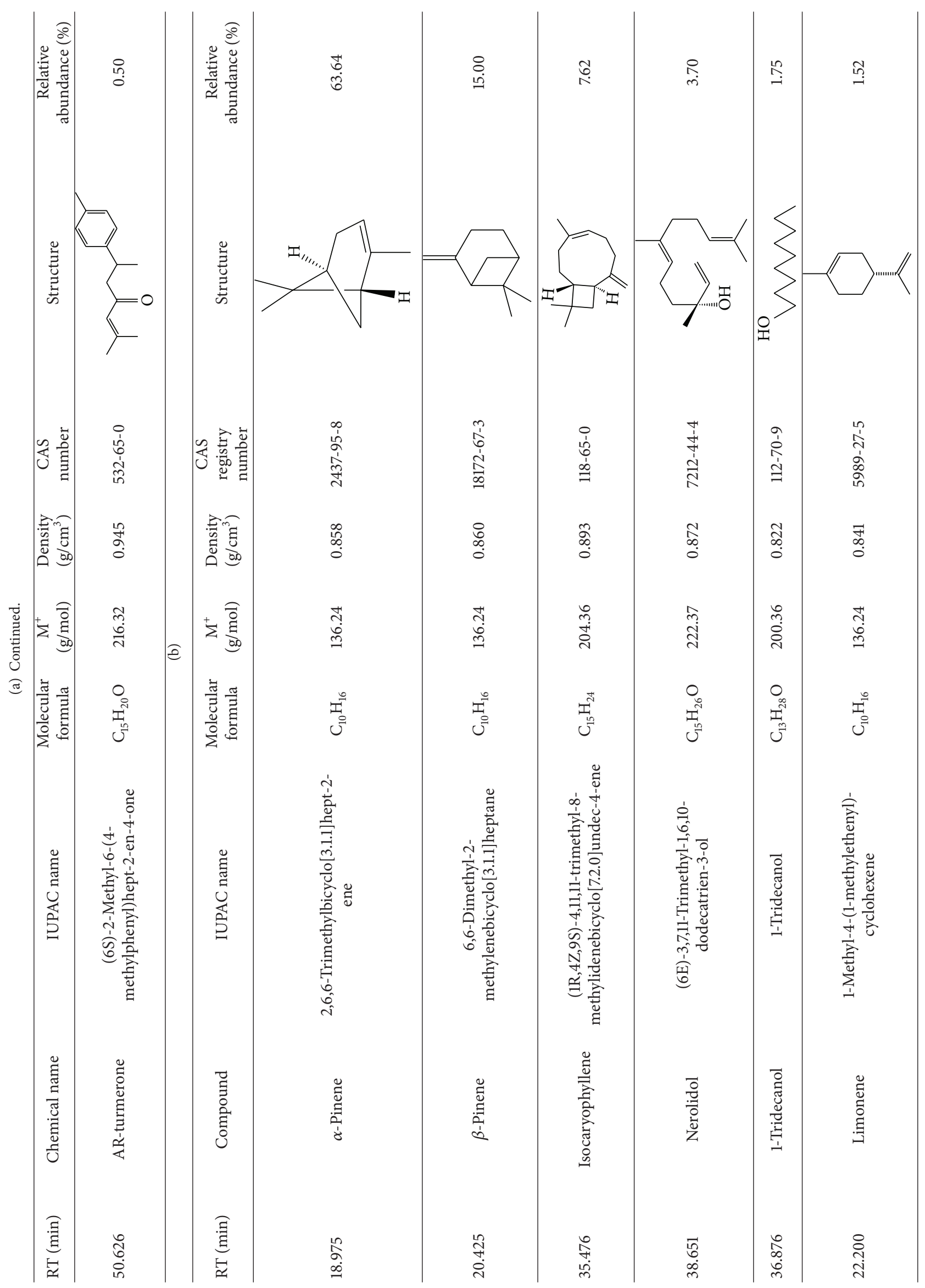




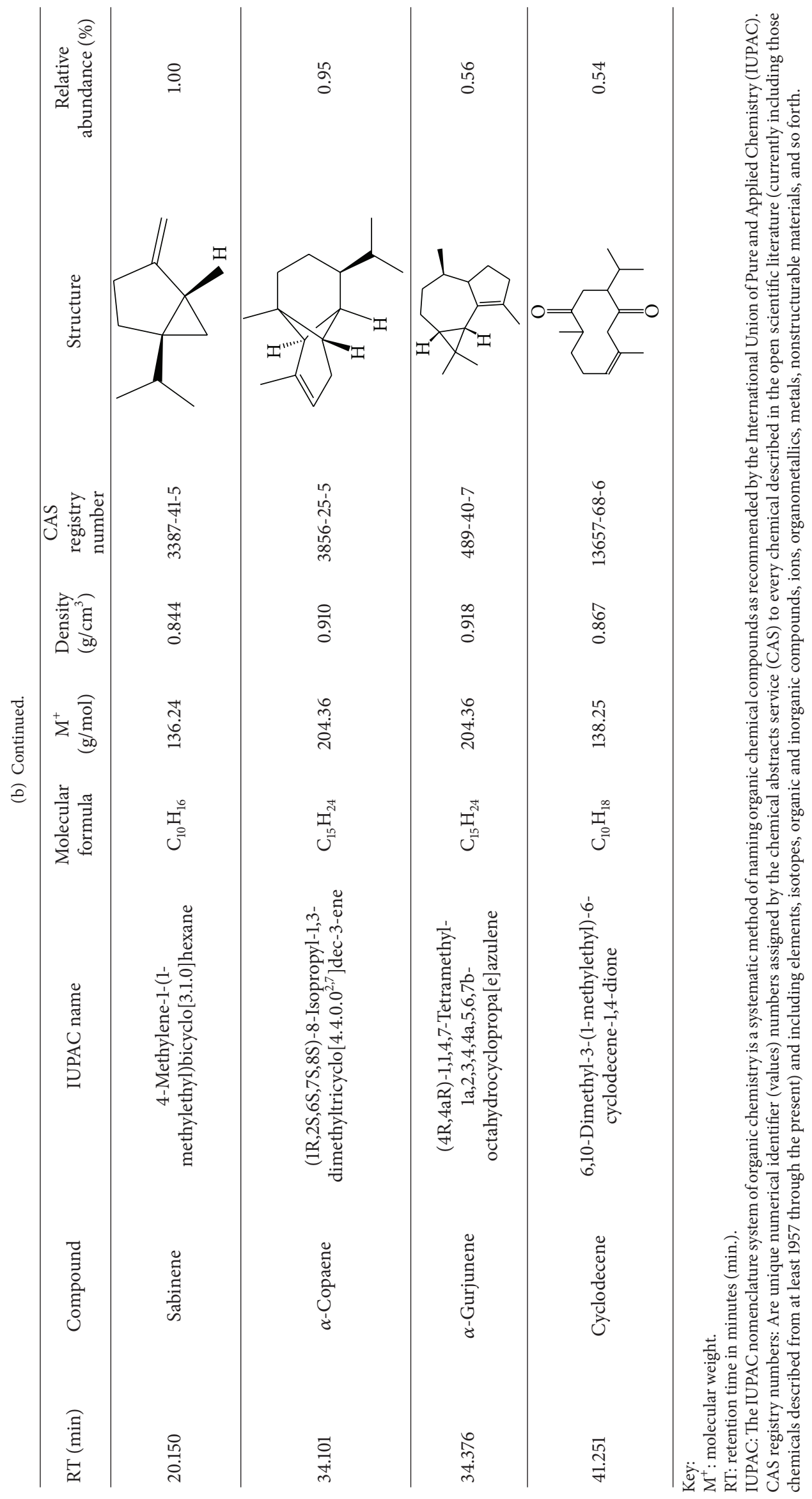


TABLE 2: Probit analysis of dose-response relationship of Tagetes minuta and Tithonia diversifolia essential oils at $\mathrm{RD}_{50}$ and $\mathrm{RD}_{75}$ generated by a regression model: Probit $[\Pi($ dosel $)]=1.1036+0.4132$ dosel for the essential oil of $T$. minuta and the regression model: Probit $[\Pi($ dosel $)]=$ $0.6401+0.4962$ dose1 for the essential oil of T. diversifolia.

\begin{tabular}{lcccc}
\hline Plant species & Repellence probability & Repellent dose $(\mathrm{mg})$ & Upper confidence limit at 95\% & Lower confidence limit at 95\% \\
\hline Tagetes minuta & 0.50 & 0.0021 & 0.0024 & 0.0019 \\
& 0.75 & 0.0915 & 0.1012 & 0.0830 \\
Tithonia diversifolia & 0.50 & 0.2629 & 0.2712 & 0.2548 \\
& 0.75 & 0.5972 & 0.6116 & 0.5835 \\
\hline
\end{tabular}

TABLE 3: Mean percent repellence $( \pm \mathrm{SE})$ of N,N-diethyl-3-methylbenzamide (DEET) evaluated in a dual-choice assay against newly emerged adult ticks, Rhipicephalus appendiculatus, at the International Centre of Insect Physiology and Ecology, Nairobi, Kenya, under the same laboratory conditions as the current studies.

\begin{tabular}{lc}
\hline Repellent dose $(\mathrm{mg})$ & Repellency (\%) \\
\hline 0.0998 & $84.0 \pm 3.9$ \\
0.00998 & $82.8 \pm 3.6$ \\
0.000998 & $75.6 \pm 4.5$ \\
0.0000998 & $70.5 \pm 3.6$ \\
\hline
\end{tabular}

Sources: Ndung'u et al. [35], 1995; Lwande et al. [37], 1998; Ndung'u et al. [27], 1999.

in T. minuta oil collected in Pretoria, South Africa) that were not detected in the other. Which constituents contribute to the repellence of the essential oil of $T$. minuta against the two tick species, respectively, must await detailed subtractive assays [55] with synthetic blends of the major constituents of the two essential oils with each component missing at a time.

Nchu and coworkers [52] also found that T. minuta oil significantly delayed moulting of $H$. rufipes engorged nymphs. In another study reported by Krishna and coworkers [56], most eggs of the coleopteran beetle, Tribolium castaneum, exposed to the vapours of essential oil of a specific genotype of T. minuta failed to hatch. Both these effects have been attributed to tagetone, one of the major constituents of T. minuta previously shown to have growth disrupting bioactivities on arthropods [57]. Since trans-tagetone is a prominent constituent of T. minuta essential oil of Bungoma chemotype (8.7\%, compared with $1.6 \%$ in the Pretoria chemotype), it will be interesting to see if similar repellent effects are also observed with nymphal $R$. appendiculatus.

In this study, essential oil of $T$. diversifolia growing in Bumgoma was found to be less repellent than that of $T$. minuta. This is reflected in its very different terpenoid profile. However, the plant is highly valued for its tick control property by the Bukusu community in Bungoma [41]. Interestingly, it is also used by the Kikuyu community in central Kenya to control livestock ticks [58] and by the Luyha and Luo communities in western Kenya to control insect pests in arable farming systems $[59,60]$. This suggests other possible modes of action of $T$. diversifolia phytochemical profile. Follow-up studies on other potential modes of action of the essential oil and nonvolatile constituents of the plant may help to shed light on this question.

\section{Conclusion}

In conclusion, the present study provides some scientific rationale for the incorporation of some botanicals in Bukusu ethnopractices in western Kenya to control tick infestations on cattle. The study also lays down some groundwork for follow-up studies on other possible effects of the phytochemicals of the plants studied and for exploiting partially refined products such as essential oils in protecting cattle against infestations by R. appendiculatus and other tick species.

\section{Conflict of Interests}

The authors declare that they have no competing interests of any kind that could inappropriately influence (bias) the publication of this paper.

\section{Funding}

This research work was jointly supported by the International Foundation for Sciences, Stockholm, Sweden, and the Organization for the Prohibition of Chemical weapons, The Hague, The Netherlands, through a Grant AB/12782-2. The first author wishes to acknowledge the financial, logistic, and material support received from the International Centre of Insect Physiology and Ecology (ICIPE) under the African Regional Postgraduate Programme in Insect Science (ARPPIS) and Wageningen University and Research Centre, Laboratory of Entomology under a sandwich Ph.D. Fellowship.

\section{Acknowledgments}

The authors wish to thank Mr. Simon M. Mathenge from the University of Nairobi Herbarium for identification of plant species; ICIPE's staff for offering their technical and administrative support, and Bukusu community ethnopractitioners and livestock farmers for their cooperation, participation and support throughout the study period. They also wish to thank the local administration of the Government of Kenya for supporting, participating, and giving permission to sample plants for isolation of essential oil.

\section{References}

[1] R. A. I. Norval, B. D. Perry, and A. S. Young, The Epidemiology of Theileriosis in Africa, Academic Press, London, UK, 1992. 
[2] J. M. Olwoch, B. Reyers, F. A. Engelbrecht, and B. F. N. Erasmus, "Climate change and the tick-borne disease, Theileriosis (East Coast fever) in sub-Saharan Africa," Journal of Arid Environments, vol. 72, no. 2, pp. 108-120, 2008.

[3] A. J. Lawrence, J. A. de Vos, and A. D. Irvin, "East coast fever," in Infectious Diseases of LivesTock With Special Reference to Southern Africa, G. R. Thomson and R. C. Tustin, Eds., Cape Town Oxford University Press, Cape Town, South Africa, 1988.

[4] K. S. Mbogo, P. D. Kariuki, N. McHardy, and R. Payne, Training Manual For Veterinary Staff on Immunization Against East Coast Fever Using the ECFiM System, Kenya Agricultural Research Institute and Overseas Development Administration of UK, Nairobi, Kenya, 1995.

[5] "Future of livestock industries in East and southern Africa," in Proceedings of the a Workshop Held at Kadoma Ranch Hotel, Zimbabwe International Livestock Centre for Africa (ILCA '92), J. A. Kategile and S. Mubi, Eds., pp. 20-23, Addis Ababa, Ethiopia, July 1992.

[6] A. Hassanali, H. Herren, Z. R. Khan, J. A. Pickett, and C. M. Woodcock, "Integrated pest management: the push-pull approach for controlling insect pests and weeds of cereals, and its potential for other agricultural systems including animal husbandry," Philosophical Transactions of the Royal Society B: Biological Sciences, vol. 363, no. 1491, pp. 611-621, 2008.

[7] S. M. Cook, Z. R. Khan, and J. A. Pickett, "The use of push-pull strategies in integrated pest management," Annual Review of Entomology, vol. 52, pp. 375-400, 2007.

[8] B. Fei and J. H. Xin, " $N, N$-diethyl- $m$-toluamide-containing microcapsules for bio-cloth finishing," American Journal of Tropical Medicine and Hygiene, vol. 77, no. 1, pp. 52-57, 2007.

[9] A. T. Mathai, K. S. Pillai, and P. B. Deshmukh, "Acute toxicity of deet to a freshwater fish, Tilapia mossambica: effect on tissue glutathione levels," Journal of Environmental Biology, vol. 10, no. 2, pp. 87-91, 1989.

[10] J. Seo, Y.-G. Lee, S.-D. Kim, C.-J. Cha, J.-H. Ahn, and H.-G. Hur, "Biodegradation of the insecticide $N, N$-diethyl- $m$-toluamide by fungi: identification and toxicity of metabolites," Archives of Environmental Contamination and Toxicology, vol. 48, no. 3, pp. 323-328, 2005.

[11] P. J. Robbins and M. G. Cherniack, "Review of the biodistribution and toxicity of the insect repellent $N, N$-diethyl-mtoluamide (DEET)," Journal of Toxicology and Environmental Health, vol. 18, no. 4, pp. 503-525, 1986.

[12] H. Qiu, H. W. Jun, and J. W. Mccall, "Pharmacokinetics, formulation, and safety of insect repellent N,N-Diethyl-3methylbenzamide (deet): a review," Journal of the American Mosquito Control Association, vol. 14, no. 1, pp. 12-27, 1998.

[13] M. C. Lewis, M. Silva, J. Sanborn, K. Pfeifer, P. J. Schreider, and E. P. Helliker, N, N-Diethyl-Meta-Toluamide (DEET): Risk Characterization Document, Medical Toxicology and Worker Health and Safety Branches: California Environmental Protection Agency, Department of Pesticide Regulation. Pesticide Registration Branch, Sacramento, Calif, USA, 2000, http://www.cdpr .ca.gov/docs/risk/rcd/deet.pdf.

[14] R. Menendenz, "El Melinitus minutifloraay la garrapata," Agricultural Review, vol. 4, pp. 219-223, 1924.

[15] K. C. Thompson, J. Roa, and T. Romero, "Anti-tick grasses as the basis for developing practical tropical tick control packages," Tropical Animal Health and Production, vol. 10, no. 3, pp. 179$182,1978$.

[16] J. F. Carroll, A. Maradufu, and J. D. Warthen Jr., "An extract of Commiphora erythraea: a repellent and toxicant against ticks,"
Entomologia Experimentalis et Applicata, vol. 53, no. 2, pp. 111116, 1989.

[17] L. J. Wilson and R. W. Sutherst, "Oviposition sites of Boophilus microplus Canestrini (Acarina: Ixodidae) in Stylosanthes and grass pastures," vol. 29, no. 2, pp. 101-105, 1990.

[18] E. C. Webb and M. David, "The efficacy of neem seed extract (Azadirachta indica) to control tick infestation in Tswana, Simmentaler and Brahman cattle," South African Journal of Animal Sciences, vol. 32, no. 1, pp. 1-6, 2002.

[19] N. R. Lersten, "Crystals of calcium compounds in Gramineae," New Phytologist, vol. 93, no. 4, pp. 633-638, 1983.

[20] F. I. J. Lagunes, D. G. Fox, R. W. Blake, and A. N. Pell, "Evaluation of tropical grasses for milk production by dual-purpose cows in Tropical Mexico," Journal of Dairy Science, vol. 82, no. 10, pp. 2136-2145, 1999.

[21] J. A. Duke, "Duke's handbook of energy crops (unpublished)," 1983, http://www.hort.purdue.edu/newcrop/duke_energy/Melinis_minutiflora.html.

[22] J. W. Chiera, R. M. Newson, and A. Maradufu, "Anti-tick properties of molasses grass, Melinis minutiflora," in Proceedings of the 5th annual report ICIPE, ICIPE Press, Nairobi, Kenya, 1977.

[23] L. Hernandez, D. Parra, and A. Ahumada, "Repellent and acaricidal activity of the oil and some chromatographic fractions of the grass Melinis minutiflora against Boophilus microplus," Revista Colombiana de Ciencias Químico Farmacéuticas, vol. 17, pp. 45-50, 1990.

[24] E. N. Mwangi, S. Essuman, G. P. Kaaya, E. Nyandat, D. Munyinyi, and M. G. Kimondo, "Repellence of the tick Rhipicephalus appendiculatus by the grass Melinis minutiflora," Tropical Animal Health and Production, vol. 27, no. 4, pp. 211-216, 1995.

[25] O. O. Dipeolu, O. A. Mongi, K. D. Punya, A. A. Latif, A. O. Amoo, and T. R. Odhiambo, "Current concepts and approach to control of livestock ticks in Africa," Discovery and Innovation, vol. 4, no. 2, pp. 35-44, 1992.

[26] M. M. Malonza, O. O. Dipeolu, A. O. Amoo, and S. M. Hassan, "Laboratory and field observations on anti-tick properties of the plant Gynandropsis gynandra (L.) Brig," Veterinary Parasitology, vol. 42, no. 1-2, pp. 123-136, 1992.

[27] M. W. Ndung'u, S. C. Chhabra, and W. Lwande, "Cleome hirta essential oil as livestock tick (Rhipicephalus appendiculatus) and maize weevil (Sitophilus zeamais) repellent," Fitoterapia, vol. 70, no. 5, pp. 514-516, 1999.

[28] M. Jacobson, Plants: the Potentials For Extracting Protein, Medicines and Other Useful Chemicals: Workshop Proceedings, Office of Technology Assessment, Washington, DC, USA, 1983.

[29] H. Panda, Aromatic Plants: Cultivation, Processing and Uses, Asia Pacific Business Press, New Delhi, India, 2004.

[30] Y. Trongtokit, Y. Rongsriyam, N. Komalamisra, P. Krisadaphong, and C. Apiwathnasorn, "Laboratory and field trial of developing medicinal local thai plant products against four species of mosquito vectors," Southeast Asian Journal of Tropical Medicine and Public Health, vol. 35, no. 2, pp. 325-333, 2004.

[31] K. R. Chauhan, J. A. Klun, M. Debboun, and M. Kramer, "Feeding deterrent effects of catnip oil components compared with two synthetic amides against Aedes aegypti," Journal of Medical Entomology, vol. 42, no. 4, pp. 643-646, 2005.

[32] B. A. Bond, Herbal Tick Repellent for Dogs, Care 2 Green Living Newsletters, 2007, http://www.care2.com/greenliving/tickrepellant.html.

[33] Nixalite of America, Flea and Tick Granular Repellent: Safe, All Natural, Biodegradable, ABC/Nixalite, Nixalite of America, East Moline, Ill, USA, 2005. 
[34] A. Maradufu, "Furanosesquiterpenoids of Commiphora erythraee and C. myrrh," Phytochemistry, vol. 21, no. 3, pp. 677-680, 1982.

[35] M. W. Ndung'u, W. Lwande, A. Hassanali, L. Moreka, and S. C. Chhabra, "Cleome monophylla essential oil and its constituents as tick (Rhipicephalus appendiculatus) and maize weevil (Sitophilus zeamais) repellents," Entomologia Experimentalis et Applicata, vol. 76, no. 3, pp. 217-222, 1995.

[36] E. N. Mwangi, A. Hassanali, S. Essuman, E. Myandat, L. Moreka, and M. Kimondo, "Repellent and acaricidal properties of Ocimum suave against Rhipicephalus appendiculatus ticks," Experimental and Applied Acarology, vol. 19, no. 1, pp. 11-18, 1995.

[37] W. Lwande, A. J. Ndakala, A. Hassanali et al., "Gynandropsis gynandra essential oil and its constituents as tick (Rhipicephalus appendiculatus) repellents," Phytochemistry, vol. 50, no. 3, pp. 401-405, 1998.

[38] R. K. Gupta and L. C. Rutledge, "Role of repellents in vector control and disease prevention," American Journal of Tropical Medicine and Hygiene, vol. 50, no. 6, pp. 82-86, 1994.

[39] R. A. Copeland, T. W. Walker, L. L. Robert, J. I. Githure, R. A. Wirtz, and T. A. Klein, "Response of wild Anopheles funestus to repellent-protected volunteers is unaffected by malaria infection of the vector," Journal of the American Mosquito Control Association, vol. 11, no. 4, pp. 438-440, 1995.

[40] WHO, International Travel and Health 1995: Vaccination Requirements and Health Advice (Vaccination Certificate Requirements For International Travel and Health Advice To Travellers), World Health Organization, Geneva, Switzerland, 1995.

[41] W. Wanzala, W. Takken, W. R. Mukabana, A. O. Pala, and A. Hassanali, "Ethnoknowledge of Bukusu community on livestock tick prevention and control in Bungoma district, western Kenya," Journal of Ethnopharmacology, vol. 140, no. 2, pp. 298324, 2012.

[42] M. Heinrich, H. Rimpler, and N. A. Barrera, "Indigenous phytotherapy of gastrointestinal disorders in a lowland Mixe community (Oaxaca, Mexico): ethnopharmacologic evaluation," Journal of Ethnopharmacology, vol. 36, no. 1, pp. 63-80, 1992.

[43] W. Wanzala, Ethnobotanicals For Management of the Brown Ear Tick, Rhipicephalus Appendiculatus in Western Kenya, Ponsen and Looijen, Wageningen, The Netherlands, 2009.

[44] K. P. Bailey, "Notes on the rearing of Rhipicephalus appendiculatus and their infection with Theileria parva for experimental transmission," Bulletin of epizootic diseases of Africa, vol. 8, pp. 33-43, 1960.

[45] A. D. Irvin and D. W. Brocklesby, "Rearing and maintaining Rhipicephalus appendiculatus in the laboratory," Ji Nan Idoon Animation Technology, vol. 21, pp. 106-112, 1970.

[46] J. F. Clevenger, "Apparatus for the determination of volatile oil," Journal of the American Pharmaceutical Association, vol. 17, no. 4, pp. 345-349, 1928.

[47] W. Wanzala, N. F. K. Sika, S. Gule, and A. Hassanali, "Attractive and repellent host odours guide ticks to their respective feeding sites," Chemoecology, vol. 14, no. 3-4, pp. 229-232, 2004.

[48] T. O. Browning, "The aggregation of questing ticks, Rhipicephalus pulchellus, on grass stems, with observations on Rhipicephalus appendicuiatus," Physiological Entomology, vol. 1, no. 2, pp. 107-114, 1976.

[49] J. W. Chiera, "The distribution and climbing behaviour of Rhipicephalus appendiculatus Neumann on grass stems," Insect Science, vol. 6, no. 2, pp. 213-215, 1985.

[50] SAS Institute Inc, Proprietary Software Release 8. 1 (TS1M0), SAS Institute, SAS Campus Drive, Cary, NC, USA, 2003.
[51] C. I. Bliss, “The method of probits," Science, vol. 79, no. 2037, pp. 38-39, 1934.

[52] F. Nchu, S. R. Magano, and J. N. Eloff, "In vitro anti-tick properties of the essential oil of Tagetes minuta L. (Asteraceae) on Hyalomma rufipes (Acari: Ixodidae)," Onderstepoort Journal of Veterinary Research, vol. 79, no. 1, pp. 1-5, 2012.

[53] E. H. Graven, L. Webber, G. Benians, M. Venter, and J. B. Gardner, "Effect of soil type and nutrient status on the yield and composition of Tagetes oil (Tagetes minuta L.)," Journal of Essential Oil Research, vol. 3, no. 5, pp. 303-307, 1991.

[54] R. A. Walker, A. Bouattour, J. L. Camicas et al., Ticks of Domestic Animals in Africa: A Guide To Identification of Species. Bioscience Reports, University of Edinburgh, Edinburgh, UK, 2003.

[55] J. Bekele and A. Hassanali, "Blend effects in the toxicity of the essential oil constituents of Ocimum kilimandscharicum and Ocimum kenyense (Labiateae) on two post-harvest insect pests," Phytochemistry, vol. 57, no. 3, pp. 385-391, 2001.

[56] A. Krishna, V. Prajapati, S. Bhasney, A. K. Tripathi, and S. Kumar, "Potential toxicity of new genotypes of Tagetes (Asteraceae) species against stored grain insect pests," International Journal of Tropical Insect Science, vol. 25, no. 2, pp. 122-128, 2005.

[57] C. O. Adedire and J. O. Akinneye, "Biological activity of tree marigold, Tithonia diversifolia, on cowpea seed bruchid, Callosobruchus maculates (Coleoptera: Bruchidae)," Annals of Applied Biology, vol. 144, no. 2, pp. 185-189, 2004.

[58] G. N. Njoroge and R. W. Bussmann, "Herbal usage and informant consensus in ethnoveterinary management of cattle diseases among the Kikuyus (Central Kenya)," Journal of Ethnopharmacology, vol. 108, no. 3, pp. 332-339, 2006.

[59] F. Adoyo, B. J. Mukalama, and M. Enyola, "Using Tithonia concoctions for termite control in Busia District, Kenya: As part of the Kenya Woodfuel and Agroforestry Programme (KWAP) farmers in the Busia District of western Kenya taking part in an on-farm experiment in pest control. Research and Information Exchange in EcologicallySound Agriculture (ILEIA)," News Letter, vol. 13, no. 4, pp. 24-25, 1997.

[60] Anonymous, Termite Control. HDRA-the Organic Organization. Ryton Organic Gardens, COVENTRY CV8 3LG, 2001, www .hdra.org.uk. 

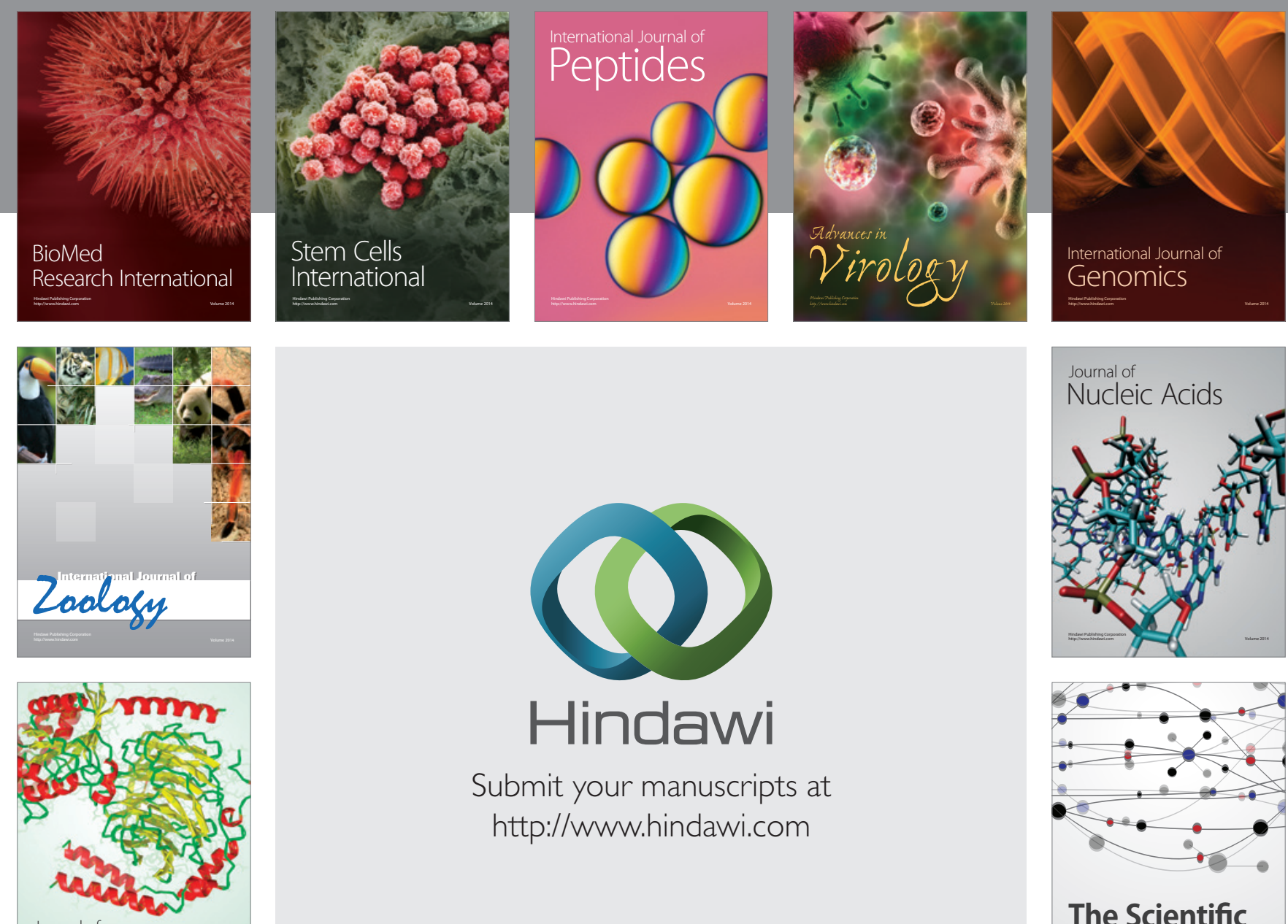

Submit your manuscripts at

http://www.hindawi.com

Journal of
Signal Transduction
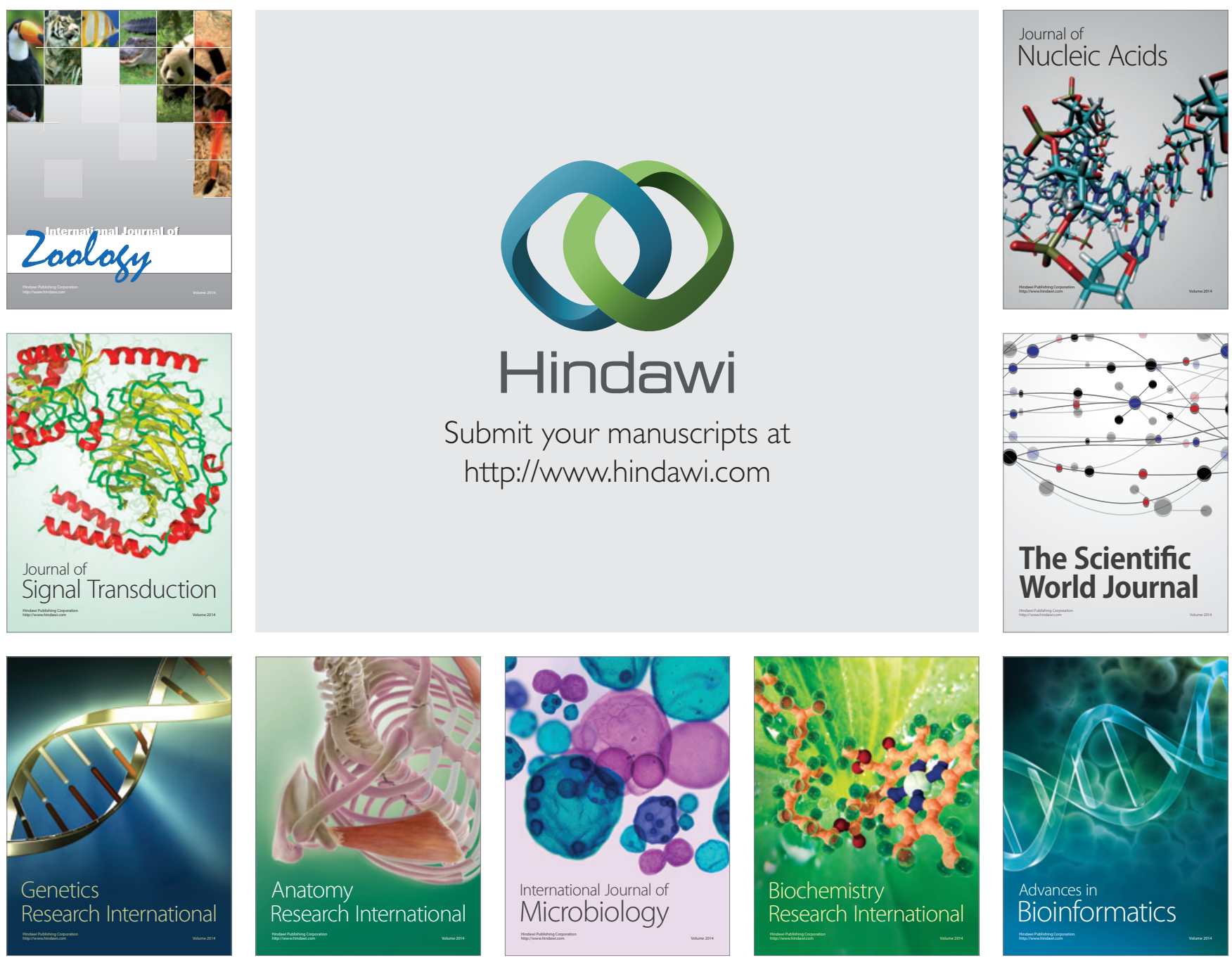

The Scientific World Journal
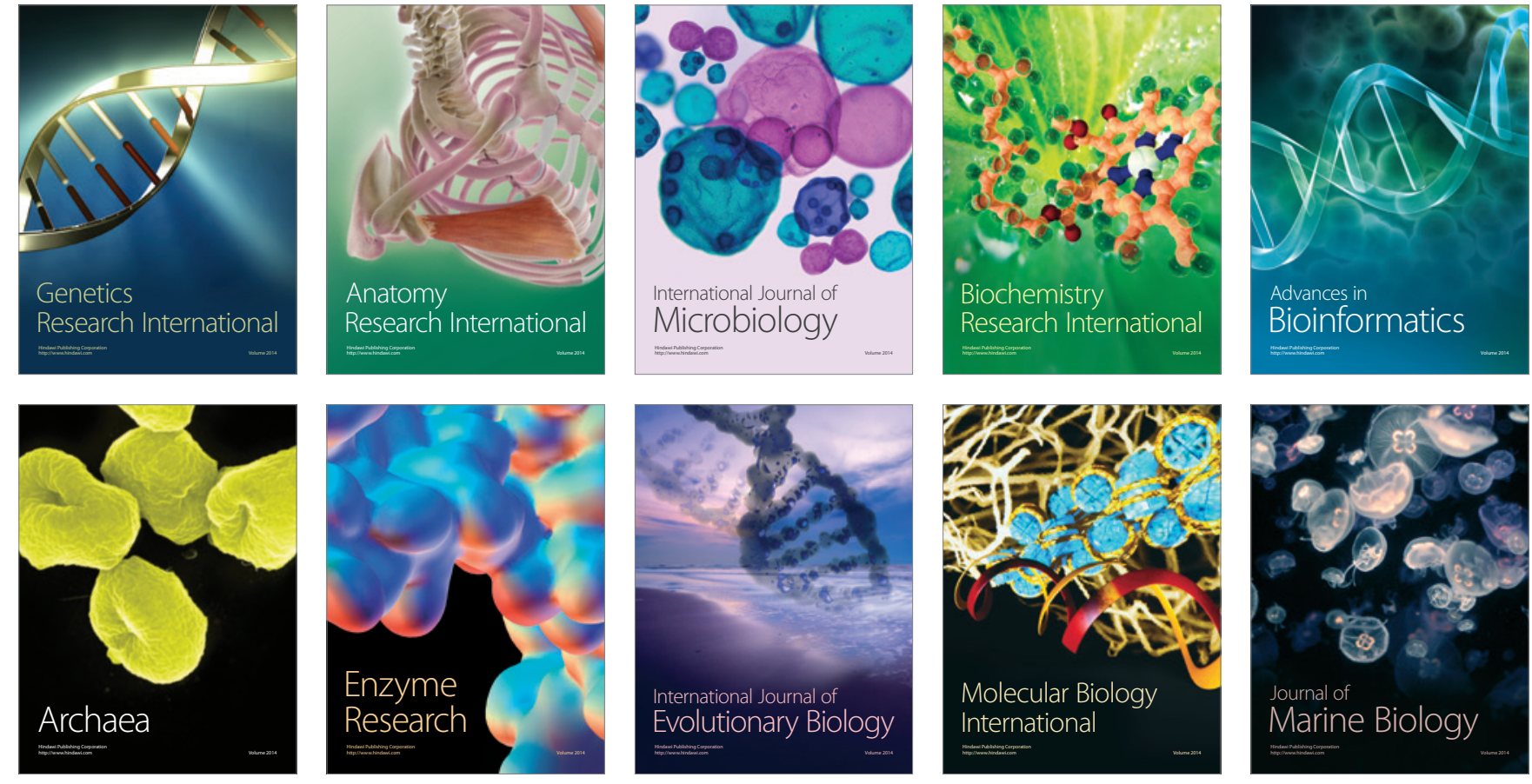